\title{
Revised analyses suggest that the lesser electric ray Narcine bancroftii is not at risk of extinction
}

\author{
John K. Carlson ${ }^{1, *}$, Adam G. Pollack ${ }^{2}$, William B. Driggers III $^{3}$, José I. Castro ${ }^{4}$, \\ Adam B. Brame ${ }^{5}$, Jennifer L. Lee ${ }^{5}$ \\ ${ }^{1}$ National Marine Fisheries Service, Southeast Fisheries Science Center — Panama City Laboratory, \\ 3500 Delwood Beach Road, Panama City, Florida 32408, USA \\ ${ }^{2}$ Riverside Technology, Inc., National Marine Fisheries Service, Southeast Fisheries Science Center - Mississippi Laboratory, \\ PO Drawer 1207, Pascagoula, Mississippi 39567, USA \\ ${ }^{3}$ National Marine Fisheries Service, Southeast Fisheries Science Center-Mississippi Laboratory, PO Drawer 1207, \\ Pascagoula, Mississippi 39567, USA \\ ${ }^{4}$ National Marine Fisheries Service, Southeast Fisheries Science Center, 75 Virginia Beach Drive, Miami, Florida 33149, USA \\ ${ }^{5}$ National Marine Fisheries Service, Southeast Regional Office, 263 13th Ave S, St. Petersburg, Florida 33701, USA
}

\begin{abstract}
Among rays inhabiting US coastal waters in the western North Atlantic Ocean, a species of potential concern is the lesser electric ray Narcine bancroftii. The most recent International Union for the Conservation of Nature (IUCN) Red List Assessment indicates the species is Critically Endangered, which represents the highest risk of extinction based on IUCN criteria. The basis of this alarming designation was a reported $98 \%$ decline in abundance based on analyses of a long-term, fisheries-independent trawl survey conducted in the northern Gulf of Mexico since 1972. The status of this species generated considerable concern within the conservation community, prompting a petition for its inclusion under the US Endangered Species Act. We critically examined all available sources of data relative to the abundance of lesser electric ray, including those utilized in the original analysis, and found lesser electric rays do not appear to be at risk of extinction. Contrary to the earlier analysis, we found no evidence of decline in the relative abundance of lesser electric rays, with trends in abundance being relatively flat with high variability. Our investigation determined that analyses of previous trawl surveys did not address major changes over time in survey design and disregarded the strong habitat preference of lesser electric rays. It is critical that the best possible information be used when considering the conservation status of a given species to minimize undue burdens and ensure that increasingly limited resources are applied to the recovery of those species that are truly in peril.
\end{abstract}

KEY WORDS: Generalized linear model · Trawl · IUCN Red List · Endangered Species Act

\section{INTRODUCTION}

In a recent systematic analysis of the threats to 1041 chondrichthyan fishes, Dulvy et al. (2014) estimated that one-quarter of species are threatened with extinction according to the International Union for the Conservation of Nature (IUCN) Red List criteria. Largebodied, shallow-water species were considered at greatest risk due primarily to overfishing (targeted and

${ }^{*}$ Corresponding author: john.carlson@noaa.gov incidental) and habitat loss, with 5 out of the 7 most threatened families being batoids (skates and rays). Of skates and rays, $1.3 \%$ of species analyzed were Critically Endangered, $2.7 \%$ were Endangered, and $6.2 \%$ were Vulnerable. Of equal concern was that $24.6 \%$ were Data Deficient (i.e. there is not enough information to assess the status of the species). The remaining species were considered to be Near Threatened $(6.0 \%)$ or Least Concern (11.0\%) (Dulvy et al. 2014).

(C) Outside the USA, the US Government 2017. Open Access under Creative Commons by Attribution Licence. Use, distribution and reproduction are unrestricted. Authors and original publication must be credited.

Publisher: Inter-Research · www.int-res.com 
Among rays inhabiting US coastal waters in the western North Atlantic Ocean, a species of particular concern is the lesser electric ray Narcine bancroftii. This small ray ranges from North Carolina to northeastern Brazil, including the Gulf of Mexico and the Caribbean Sea (de Carvalho 1999). It is locally abundant in specific habitats as it occurs almost exclusively on sandy, hard-bottom habitats, around barrier islands and beach surf zones (Coles 1910, Bigelow \& Schroeder 1953, Rudloe 1989).

The most recent IUCN Red List Assessment of the lesser electric ray in the western North Atlantic Ocean indicated the species is Critically Endangered under criteria A2abd, 3bd, and 4bd (de Carvalho et al. 2007), which represents the highest risk of extinction based on IUCN criteria. Based on an analysis of trawl data from the NOAA Fisheries Service and the Southeast Area Monitoring and Assessment Program (SEAMAP), the lesser electric ray in the northern Gulf of Mexico was reported to have declined by $98 \%$ since 1972 (Shepherd \& Myers 2005). Similarly, de Carvalho et al. (2007) reported that data from the Reef Environmental Education Foundation (REEF) program suggested that lesser electric rays have become extremely rare in recent years, with diverrecorded sighting rates being extremely low along the east coast of Florida, the Gulf of Mexico, and the northwestern Caribbean Sea. However, the assessment by de Carvalho et al. (2007) was based largely on a single abundance trend with few positive observations (78 individuals collected over $30 \mathrm{yr}$ ) and unpublished, anecdotal information (i.e. there was no formal analysis conducted for the REEF data series).

Recently, the Critically Endangered status of the lesser electric ray determined during the Red List Assessment formed the basis of a petition by WildEarth Guardians to include the species on the US Endangered Species List (United States Federal Register 76 FR 15947, 79 FR 4877). Under the US Endangered Species Act, an endangered species is defined as 'any species that is in danger of extinction throughout all or a significant portion of its range'. Due to limited funds to protect and rebuild adversely impacted populations, conservation priorities are often based on the probability of extinction of a species (Marris 2007), thus it is imperative that such a listing be based on a sound assessment. Moreover, determining whether a species is truly at risk of extinction is particularly important because the determination can indicate that current conservation and management regulations are not working for this species and other similar species. As limited resources are best used in protecting species that are truly at risk of extinction, unwarranted listings can draw resources away from species in peril. Here, we provide a reassessment of the population trajectories of the lesser electric ray in the western North Atlantic.

\section{METHODS}

We attempted to find any and all abundance data related to the species' status. This included a review of the known scientific literature and communication with state and federal monitoring agencies. We reanalyzed the SEAMAP Gulf of Mexico, SEAMAP South Atlantic and REEF data series because these data were the basis of the IUCN Red List assessment (de Carvalho et al. 2007). With regard to other data sets, either the areas were sampled too infrequently or the number of lesser electric rays captured was too low to be meaningful.

\section{Gulf of Mexico Mississippi Laboratory - SEAMAP data}

NOAA Fisheries Service-Mississippi Laboratory has conducted standardized fall trawl surveys since 1972 as part of a resource assessment program. In 1982, a summer trawl survey was added and conducted through SEAMAP, which is a collaborative effort between federal, state and university programs designed to collect, manage and distribute fishery independent data. Beginning in 1987, the Fall Trawl survey was conducted as part of the standardized trawl sampling under SEAMAP. The primary objective of these trawl surveys was to collect data on the abundance and distribution of demersal organisms in the northern Gulf of Mexico. The surveys provide an important source of fisheries-independent information on many commercially and recreationally important species throughout the Gulf of Mexico (Pollack \& Ingram 2014, Pollack \& Ingram 2015). A full description of the historic and current surveys can be found in Nichols (2004) and Rester (2015). In regard to the lesser electric ray, it is important to note that currently in the SEAMAP and Mississippi Laboratory (MSLABS) databases, the species is misidentified as $N$. brasiliensis, which is not known to occur in the Gulf of Mexico. For this analysis, all $N$. brasiliensis and Narcine sp. were treated as $N$. bancroftii.

Building upon the work of Shepherd \& Myers (2005), who examined trends in elasmobranch abun- 
dance utilizing MSLABS/SEAMAP data, we re-analyzed those data and extended the time series through 2013. While Shepherd \& Myers (2005) used the longest continuous temporal coverage (19722002), for the areas between 10 and $110 \mathrm{~m}$ in depth near Alabama, Mississippi and Louisiana, we analyzed 3 separate time series because of major changes in survey design and survey coverage between 1972-1986 and 1987-2013 (see Pollack \& Ingram 2014 for details). These series were Fall Trawl
1972-1986, Fall SEAMAP 1988-2013 and Summer SEAMAP 1982-2013. The fall of 1987 survey was omitted from analysis because the cruise track differed from that of all the other surveys (counterclockwise around the northern Gulf of Mexico and missed half of the area off Texas due to weather). This approach to disaggregate the survey due to changes in design has been accepted in previous stock assessments for sharks that utilized this data source (e.g. NMFS 2013).

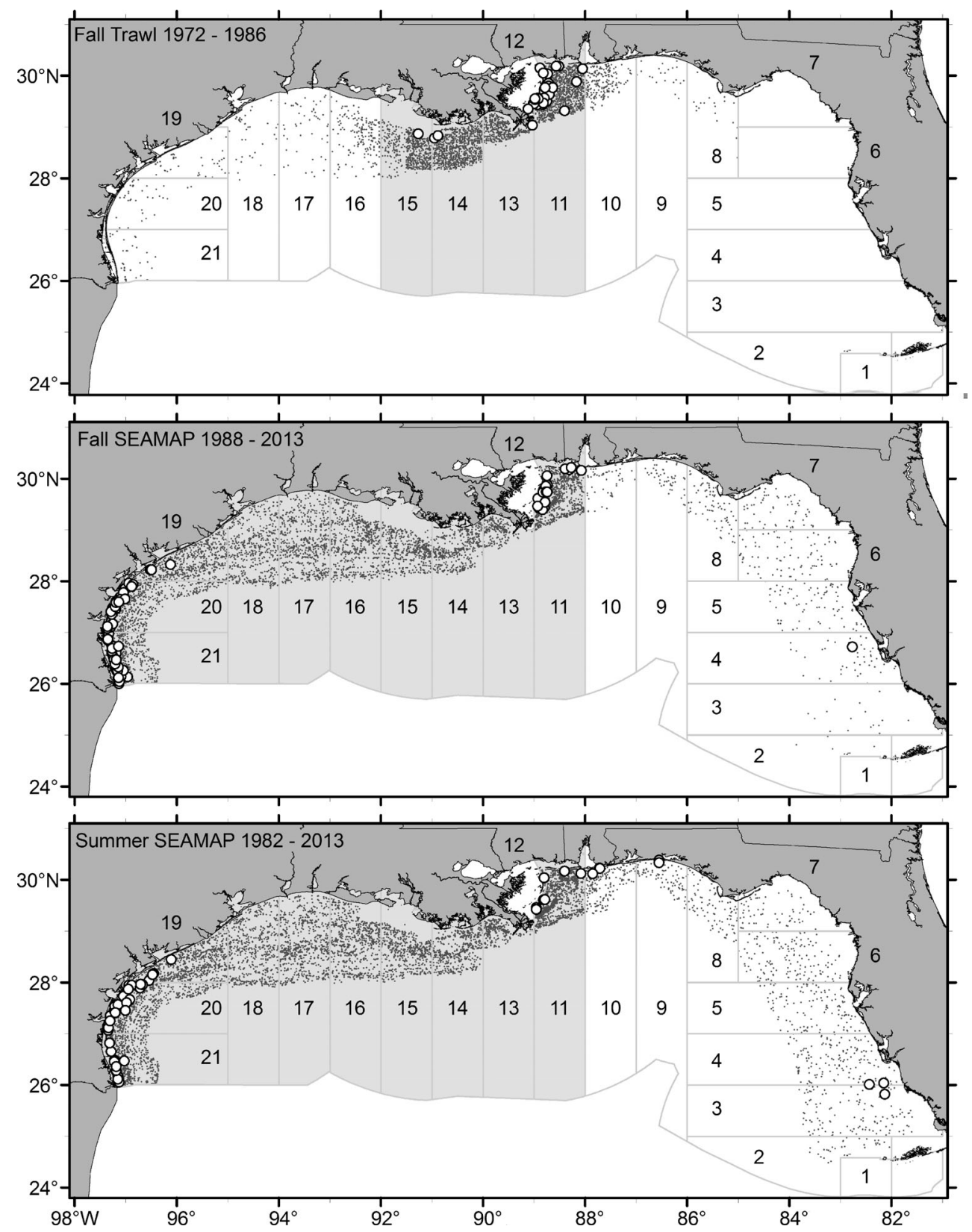

Fig. 1. Capture locations of lesser electric rays in the Gulf of Mexico. Open circles indicate positive capture locations, while small closed circles are trawl locations. NMFS Statistical Zones are indicated (www.sefsc.noaa.gov/images/stssn_statzone _gulf.gif) 
The abundance index constructed for Fall Trawl 1972-1986 was limited to National Marine Fisheries Service (NMFS) statistical zones 11, 13, 14 and 15 (Fig. 1). Sampling outside of these zones was inconsistent; therefore, the analysis was limited to this core area. In addition, all stations deeper than $75 \mathrm{~m}$ were removed from the dataset since there were no records of lesser electric rays occurring at those depths from any year of the survey. There are, in actuality, only 2 records in the entire data set of lesser electric ray occurring deeper than $36.5 \mathrm{~m}, 1$ in 1972 at $42 \mathrm{~m}$ and 1 in 1975 at $64 \mathrm{~m}$ (depths for these stations were verified by the NOAA National Geophysical Data Center, www.ngdc.noaa.gov/ mgg/coastal/crm.html). The second index constructed was Fall SEAMAP 1988-2013. Following the analysis for the first time series, data for this index were limited to NMFS statistical zones 10-21 (excluding 12), and at stations shallower than $31 \mathrm{~m}$. The third index constructed was Summer SEAMAP 1982-2013. Data for this index were limited to NMFS statistical zones 10-21 (excluding 12), and at stations shallower that $33 \mathrm{~m}$.

Delta-lognormal modeling methods were used to estimate relative abundance indices for the lesser electric ray (Pennington 1983, Bradu \& Mundlak 1970). The index is a mathematical combination of yearly abundance estimates from 2 distinct generalized linear models. A binomial (logistic) model described proportion of positive abundance values (i.e. presence/absence) assuming a binomial error distribution and a logit link function. A lognormal model described variability in only the nonzero abundance data (number per tow hour) assuming a lognormal distribution (e.g. Lo et al. 1992). A Delta-lognormal modeling approach was selected here as this is one of the most widely used approaches in the stock assessment literature for standardizing data sets that corrects for factors unrelated to abundance (Maunder \& Punt 2004), and because the response variable, number per tow hour, is not count data, assuming a lognormal distribution was appropriate.

The binomial and lognormal submodels were built using a backward selection procedure based on type 3 analyses with an inclusion level of significance of $\alpha=0.05$. Covariates considered in the analysis that may have affected abundance included year, area, water depth, and time of day (Table 1). Regardless of its level of significance, year was retained in all submodels as a random variable. This allowed for the estimation of the annual indices, which was the main objective of the standardization process, but also accounted for the variability associated with year interactions. Final models were then selected based on Akaike's information criterion (AIC).

The standardized CPUE values for the Delta models were calculated as the product of the expected probability of a non-zero catch and the expected conditional catch rate for tows that had a non-zero catch. The expected probability and expected conditional catch rate were the least square means of the factor year from each of the 2 analyses that constitute an analysis using the Delta model approach. All models were fit using a SAS macro, GLIMMIX (glmm 800MaOB.sas; Russ Wolfinger, SAS Institute) and the MIXED procedure in SAS statistical computer software.

\section{South Atlantic SEAMAP data}

A similar SEAMAP survey occurs off the southeast US Atlantic Coast (Fig. 2). Samples are collected by trawl from the coastal zone between Cape Hatteras, North Carolina, and Cape Canaveral, Florida, with surveys conducted in spring (early April to mid-May), summer (mid-July to early August), and fall (October to mid-November). Stations are randomly selected from a pool of stations within each stratum. The number of stations sampled in each stratum is determined by optimal allocation. From 1990 to 2000, the survey sampled 78 stations each season within 24 shallowwater strata. Beginning in 2001, the number of stations sampled each season in the 24 shallow-water strata increased to 102. Strata are delineated by the $4 \mathrm{~m}$ depth contour inshore and the $10 \mathrm{~m}$ depth contour offshore. In previous years (1990-2000), stations were sampled in deeper strata with station depths ranging from 10 to $19 \mathrm{~m}$ in order to gather data on the reproductive condition of commercially important penaeid shrimp. Those strata were abandoned in 2001 in order to intensify sampling in the shallower depth zone. Further details are available in Eldridge (1988).

Similar to the SEAMAP Gulf of Mexico data, we used a delta-lognormal model to develop trends in abundance (number per tow) for lesser electric rays in the Atlantic Ocean off the southeast US Atlantic Coast. Covariates considered in this analysis included year, season, area, and sampling statistical zone (Table 1).

\section{REEF data}

The Reef Environmental Education Foundation (REEF; www.reef.org) compiles a dataset that com- 
Table 1. Candidate covariates hypothesized to affect catch rates of lesser electric rays. Covariates were considered in both the binomial and lognormal models

\begin{tabular}{|c|c|c|c|}
\hline Data series & Variable & Tyре & Description \\
\hline \multirow[t]{4}{*}{ Fall Trawl 1972-1986 } & Year & Categorical & $1972-1986$ \\
\hline & Area & Categorical & $\begin{array}{l}\text { Louisiana (NMFS statistical zones 13-15), } \\
\text { Mississippi/Alabama (NMFS statistical zone 11) }\end{array}$ \\
\hline & Depth & Continuous & $9.1-73.1 \mathrm{~m}$ \\
\hline & Time of day & Categorical & Day/night \\
\hline \multirow[t]{4}{*}{ Fall SEAMAP 1988-2013 } & Year & Categorical & $1988-2013$ \\
\hline & Area & Categorical & $\begin{array}{l}\text { Texas (NMFS statistical zones 18-21), Louisiana } \\
\text { (NMFS statistical zones 13-17), Mississippi/ } \\
\text { Alabama (NMFS statistical zones 10-11) }\end{array}$ \\
\hline & Depth & Continuous & $9.1-31.1 \mathrm{~m}$ \\
\hline & Time of day & Categorical & Day/night \\
\hline \multirow[t]{4}{*}{ Summer SEAMAP 1982-2013 } & Year & Categorical & $1982-2013$ \\
\hline & Area & Categorical & $\begin{array}{l}\text { Texas (NMFS statistical zones 18-21), Louisiana } \\
\text { (NMFS statistical zones 13-17), Mississippi/ } \\
\text { Alabama (NMFS statistical zones 10-11) }\end{array}$ \\
\hline & Depth & Continuous & $9.1-31.1 \mathrm{~m}$ \\
\hline & Time of day & Categorical & Day/night \\
\hline \multirow[t]{4}{*}{ SEAMAP South Atlantic } & Year & Categorical & $1989-2013$ \\
\hline & Season & Categorical & Spring, summer, fall \\
\hline & State & Categorical & Florida, Georgia, South Carolina, North Carolina \\
\hline & Stratum & Categorical & NMFS statistical zones 21-67, odd numbers \\
\hline \multirow[t]{7}{*}{ REEF } & Year & Categorical & $1993-2013$ \\
\hline & Area & Categorical & $\begin{array}{l}\text { Florida, northwestern Caribbean Sea, Continen- } \\
\text { tal Caribbean Sea, Antilles }\end{array}$ \\
\hline & Habitat & Categorical & Mixed, reef, sand \\
\hline & Season & Categorical & Winter, spring, summer, fall \\
\hline & Experience & Categorical & Novice or expert \\
\hline & Bottom temperature & Continuous & Depth recorded by the diver \\
\hline & Visibility & Continuous & Visibility recorded by the diver \\
\hline
\end{tabular}

prises of more than 100000 visual surveys conducted by recreational divers during their daily SCUBA dive activities (REEF 2014). This dataset has been previously utilized for evaluating elasmobranch species abundance trends (e.g. Ward-Paige et al. 2011 and references therein). Because these dives vary in duration, location and skill level (experience), we also applied a Delta-lognormal model, as described earlier, to examine standardized rates of change in sighting frequency as an index of abundance. We initially considered geographic area as a covariate based on the 8 major sampling regions in the Tropical Western Atlantic Zone of the REEF database (www.reef.org/db/zonecodes/twa). However, due to the low occurrence of electric rays in the overall data set, we refined the data to remove areas with lower occurrences of electric ray and combined areas of similar geographic scope. Areas of low occurrence that were removed from the analysis included the Gulf of Mexico, the Bahamas, and Bermuda. We combined the Greater and Lesser Antilles and the east coast of Florida and Florida Keys as 2 categorical variables, Antilles and Florida, respectively. We further removed the habitat types grass, ledges, rubble, artificial and open ocean. However, it should be noted that the habitats with the highest observations of electric ray were in areas of the highest SCUBA diving activity and not necessarily the habitat preferred by lesser electric rays. We also considered diver skill level (experienced or novice), season, water temperature and water visibility as covariates (Table 1). 


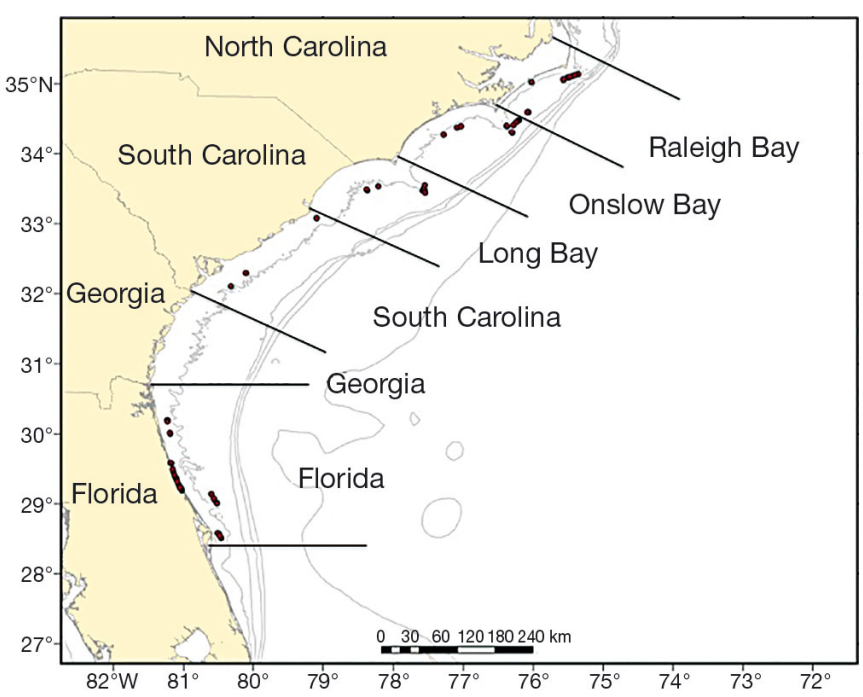

Fig. 2. Capture locations (closed circles) of lesser electric rays and sampling strata for the US South Atlantic Southeast Area Monitoring and Assessment Program (SEAMAP) survey. Shallow water stations include Stns 21-29 in Florida, 31-39 in Georgia, 41-49 in South Carolina, 51-55 in Long Bay, 57-63 in Onslow Bay, and 65-67 in Raleigh Bay. Isobaths (from shore) show 10, 50, 100, and $200 \mathrm{~m}$ depths

\section{RESULTS}

Within the northern Gulf of Mexico, a total of 9876 tows were included in the analysis, with 624 lesser electric rays captured. Most captures occurred off the coast of Mississippi, Louisiana, and Texas (Fig. 1). For the Fall Trawl 1972-1986 series, only year was retained as a covariate in the binomial submodel, while year and depth were retained in the lognormal submodel. Year, area, depth and time of day were the most significant covariates in the binomial submodel for the Fall SEAMAP 1988-2013 abundance series, while year and time-of-day were retained in the lognormal submodel. For the Summer SEAMAP 1982-2013 time series, year, area, depth and time of day were the most significant covariates in the binomial submodel, while year was retained for the lognormal submodel. All 3 Gulf of Mexico SEAMAP time series were relatively flat, with peaks in abundance scattered throughout the abundance trend (Fig. 3).

In the US South Atlantic Ocean, the relative abundance for lesser electric rays was also relatively flat, with peaks in abundance of different magnitudes found about every 5-10 yr (Fig. 4). A total of 110 tows recorded lesser electric rays, representing $1.4 \%$ of the total number of tows. Most captures occurred in waters less than $10 \mathrm{~m}$ deep from North Carolina to the coast of Florida (Fig. 2). Year was the only signif-

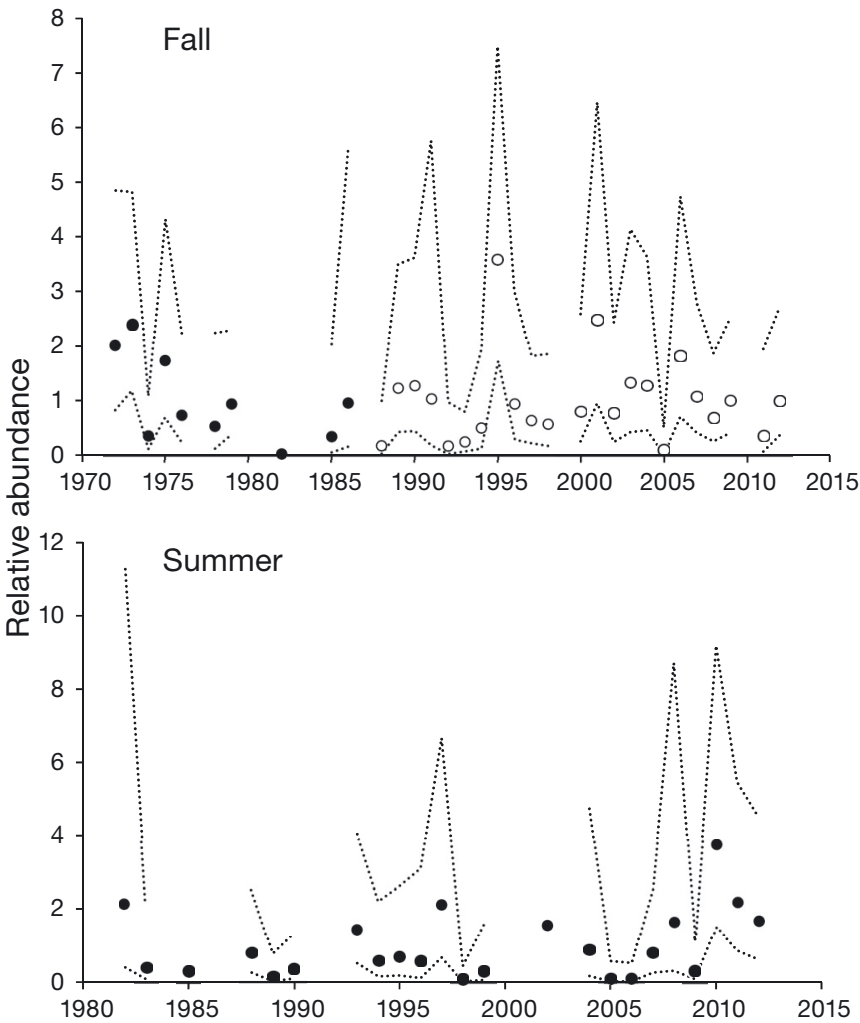

Fig. 3. Annual standardized index of abundance for lesser electric rays from the Gulf of Mexico Southeast Area Monitoring and Assessment Program (SEAMAP). The Fall Trawl survey is disaggregated to 1972-1986 (closed circles) and 1988-2013 (open circles) due to changes in survey design (see 'Methods'). The Summer SEAMAP survey was collected from 1982 to 2013. Relative abundance (number of lesser electric rays collected per trawl hour) is expressed as the year's estimated mean index divided by the maximum estimated yearly mean index in each time series. Upper and lower $95 \%$ confidence limits are indicated by dotted lines

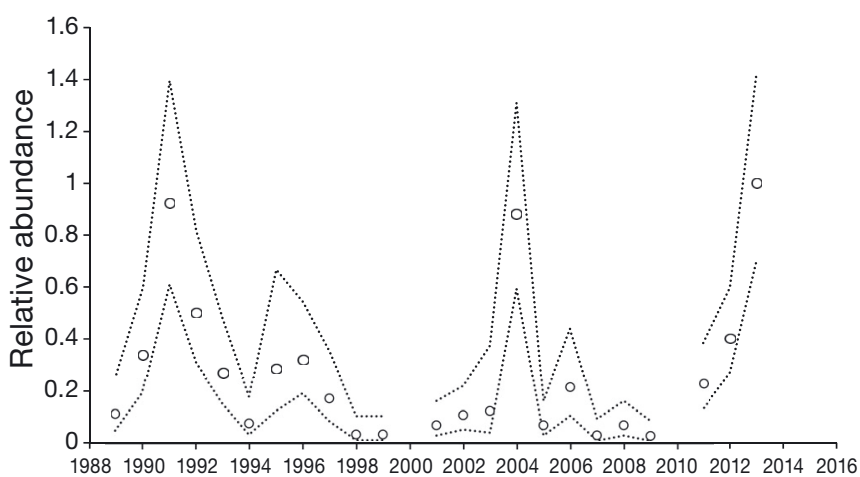

Fig. 4. Annual standardized index of abundance for lesser electric rays from the US south Atlantic Southeast Area Monitoring and Assessment Program (SEAMAP). Relative abundance (number of lesser electric rays collected per trawl hour) is expressed as the year's estimated mean index divided by the maximum estimated yearly mean index in each time series. Upper and lower $95 \%$ confidence limits are indicated by dotted lines 


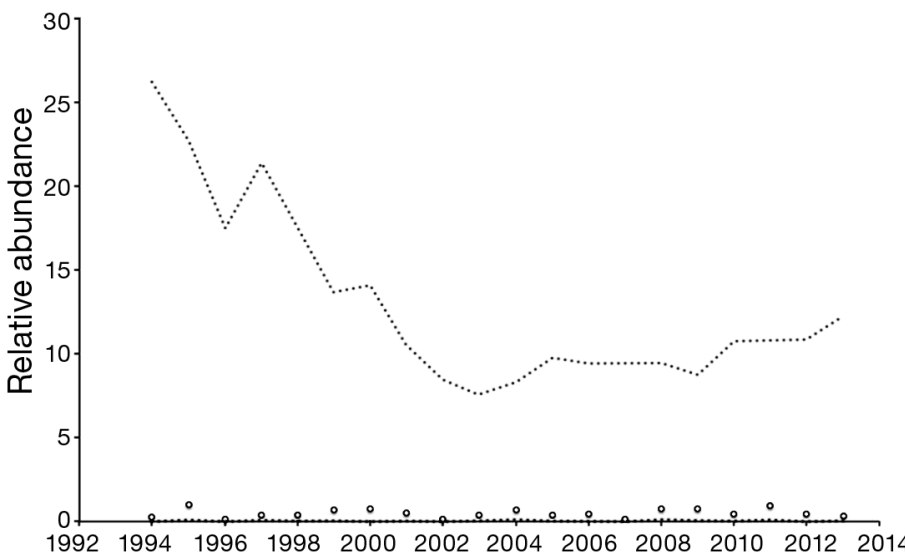

Fig. 5. Annual standardized index of abundance for lesser electric rays from the Reef Environmental Education Foundation (REEF) diver survey data. Relative abundance (sightings of lesser electric rays per dive) is expressed as the year's estimated mean index divided by the maximum estimated yearly mean index in each time series. Upper 95\% confidence limit (CL) is indicated by dotted line (lower 95\% CL overlaps $X$-axis)

icant covariate determined for both the binomial and lognormal models.

In the refined REEF database, lesser electric rays were observed on $0.5 \%$ of diver surveys. Lesser electric rays were reported primarily in the Antilles over reef and mixed bottom. The average depth at which diver sightings occurred was about $5 \mathrm{~m}$. The final covariates retained in the model were year, area and season. The trend in number of occurrences was relatively flat and similar to the other data series that showed high fluctuation across years. Due to the low encounter rate, there was high uncertainty in the abundance trend (Fig. 5).

\section{DISCUSSION}

Based on the relative abundance trends from the 3 independent sources we analyzed, lesser electric rays are not in immediate risk of extinction in US waters of the western North Atlantic Ocean. Furthermore, no evidence of a decline in the relative abundance of lesser electric rays over time was found among the abundance trends generated in this study. In all data sets examined, the trend in abundance is relatively flat, with high variability within each time series. This is not surprising based on the clumped and patchy distribution over shallow, sandy habitats utilized by this species in the western North Atlantic Ocean (Rudloe 1989, McEachran \& de Carvalho 2002). Rudloe (1989) reported catching 3913 electric rays at several stations from Cape San Blas to Alligator Point, Florida, from March 1985 to March 1987, further demonstrating the species' abundance in its preferred habitat. The patchy distribution is also verified when comparing substrate type and collection locations for lesser electric rays within the SEAMAP data. This is particularly true when considering that the sampling sites of the Gulf of Mexico SEAMAP surveys is dominated by mud-bottom habitats, habitats not preferred by the species (Fig. 6).

Based on interactions with commercial fishing gear and the species' life history, impacts from overutilization are unlikely to cause the species to be at risk of extinction. Although little information is available on the life history of lesser electric rays, anecdotal studies suggest rapid growth and early age at maturity (Rudloe 1989). While it is generally regarded that elasmobranchs exhibit life history traits that make

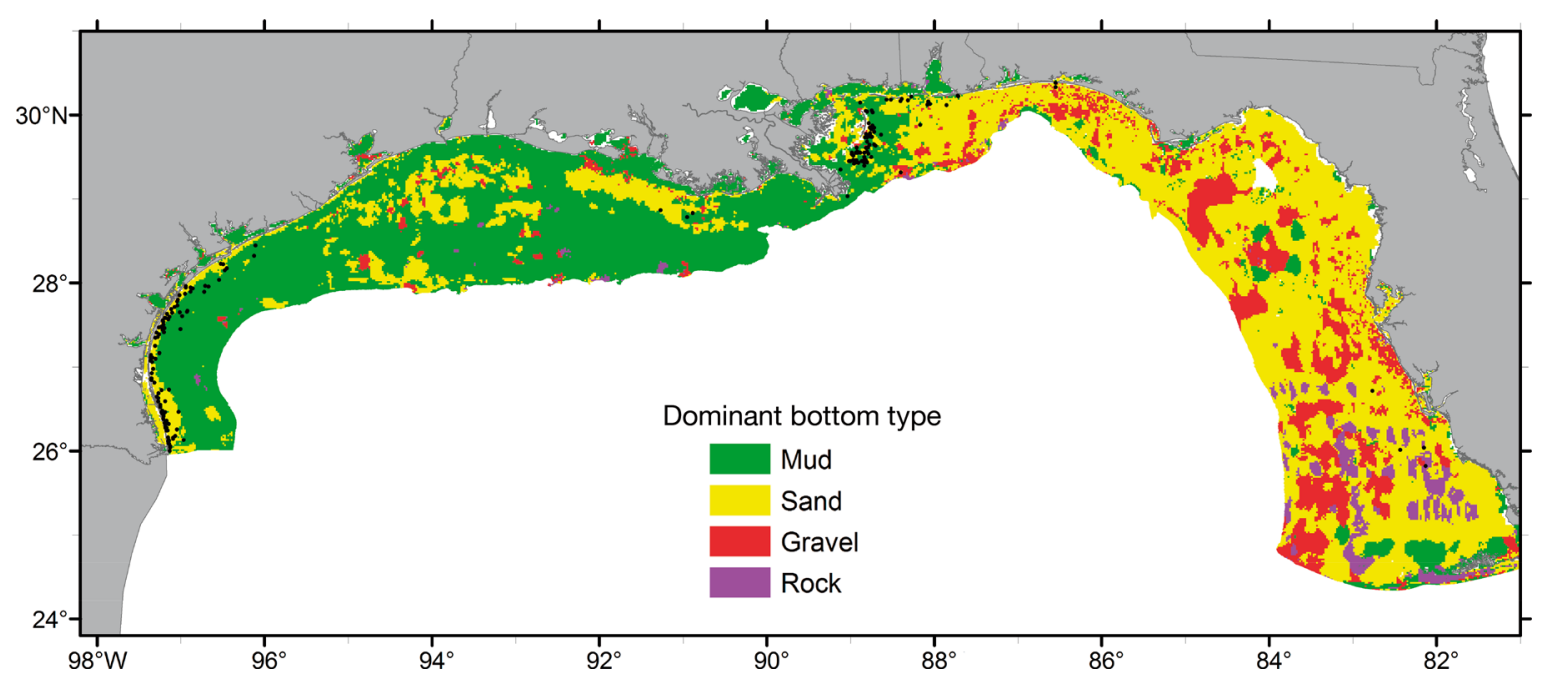

Fig. 6. Distribution of lesser electric ray capture locations and dominant bottom type in the northern Gulf of Mexico. Closed black circles represent capture locations 
them more susceptible to exploitation (e.g. low fecundity, late age of maturity, slow growth), the limited evidence suggests lesser electric rays exhibit life history traits that can withstand moderate anthropogenic mortality levels and have a higher potential to recover from exploitation and stochastic events. Moreover, levels of bycatch from the US shrimp trawl fishery are low primarily because the shrimp fishery operates in areas where lesser electric rays are not found (e.g. muddy sediment types).

Large declines in abundance of lesser electric rays in the Gulf of Mexico were reported in the original analysis by Shepherd \& Myers (2005). Those authors did not address the fact that major changes were made in the trawl survey design when the Fall Trawl survey was brought under SEAMAP, which resulted in a drastic decrease in the intensity of sampling within the central Gulf of Mexico. This decrease reduced the probability that randomly selected sampling sites would occur on spatially discrete areas of suitable habitat for lesser electric rays in the region. Walters (2003) noted that failure to recognize assumptions about abundance trends in spatial cells that were not sampled at all or early or late in a time series can result in exaggerated abundances trends (e.g. hyperdepletion; Hilborn \& Walters 1992) and the appearance that a population has declined much more than it actually has. In addition, by only focusing on the trawls off Mississippi, Shepherd \& Myers (2005) did not include all the captures $(\mathrm{n}=$ 143) that occurred off south Texas, an area with more expansive, shallow, sand-bottom habitats preferred by lesser electric rays. Further, the higher abundances in the early years of the survey were also likely inflated because many of the lesser electric rays were marked as either 'Sampled' and those later in the time series were marked 'Select' (Table 2). Shepherd \& Myers (2005) reported only 78 lesser electric rays were captured during the course of the survey from 1972 to 2002, the time period they analyzed; however, there were actually 349 individuals captured during that time period. The total number of individuals for species categorized as 'Sampled' is based on an extrapolation of the

Table 2. Number of lesser electric rays that were marked as 'Sample' and 'Select' (see 'Discussion') during the MSLABS/SEAMAP Trawl Surveys. If the 2 numbers are equal, every lesser electric ray was removed from the catches and counted. Core refers to samples taken from statistical zones 11-15, and SEAMAP expansion (SEAMAP Exp) refers to those from statistical zones 16-21. Italic values in parentheses are the number of lesser electric rays captured shallower than $9 \mathrm{~m}$. Shaded blocks were not sampled during the corresponding time period. Blank cells (outside of the gray shading) indicate zero

\begin{tabular}{|c|c|c|c|c|c|c|c|c|}
\hline \multirow{3}{*}{ Year } & \multicolumn{4}{|c|}{$\longrightarrow$ Fall } & \multicolumn{4}{|c|}{$\longrightarrow$ Summer } \\
\hline & \multirow{2}{*}{\multicolumn{2}{|c|}{$\begin{array}{l}\text { SEAMAP Exp } \\
\text { Sample Select }\end{array}$}} & \multicolumn{2}{|c|}{ Core } & \multicolumn{2}{|c|}{ SEAMAP Exp } & \multicolumn{2}{|c|}{ Core } \\
\hline & & & Sample & Select & Sample & Select & Sample & Select \\
\hline 1972 & & & 16 & 38 & & & & \\
\hline 1973 & & & 48 & 127 & & & & \\
\hline 1974 & & & 7 & 9 & & & & \\
\hline 1975 & & & 9 & 28 & & & & \\
\hline 1976 & & & 21 & 21 & & & & \\
\hline 1977 & & & & & & & & \\
\hline 1978 & & & 32 & 32 & & & & \\
\hline 1979 & & & 13 & 37 & & & & \\
\hline 1980 & & & & & & & & \\
\hline 1981 & & & & & & & & \\
\hline 1982 & & & 1 & 1 & 2 & 9 & & \\
\hline 1983 & & & & & 1 & 1 & & \\
\hline 1984 & & & & & & & & \\
\hline 1985 & & & 4 & 4 & 1 & 1 & & \\
\hline 1986 & & & 1 & 4 & & & & \\
\hline 1987 & & & 3 & 5 & & & & \\
\hline 1988 & & & 1 & 3 & & & 7 & 14 \\
\hline 1989 & 3 & 3 & $1(32)$ & $6(43)$ & & & & \\
\hline 1990 & 1 & 1 & $4(9)$ & $11(19)$ & & & 6 & 6 \\
\hline 1991 & & & $16(4)$ & $16(4)$ & & & & \\
\hline 1992 & 1 & 1 & & & & & & \\
\hline 1993 & 3 & 3 & (6) & (17) & 9 & 9 & & \\
\hline 1994 & 3 & 3 & $(8)$ & $(8)$ & 2 & 2 & & \\
\hline 1995 & 23 & 30 & 1 & 1 & 2 & 2 & & \\
\hline 1996 & 9 & 9 & $(6)$ & $(6)$ & 2 & 2 & & \\
\hline 1997 & 4 & 6 & & & 7 & 14 & & \\
\hline 1998 & 3 & 3 & 1 & 2 & & & 1 & 1 \\
\hline 1999 & & & (1) & (1) & & & 2 & 2 \\
\hline 2000 & 4 & 4 & & & & & & \\
\hline 2001 & 8 & 10 & 2 & 4 & & & & \\
\hline 2002 & 3 & 3 & & & 8 & 10 & & \\
\hline 2003 & 7 & 10 & (1) & (1) & & & & \\
\hline 2004 & 12 & 12 & (1) & (1) & 6 & 6 & & \\
\hline 2005 & 1 & 2 & (1) & (1) & & & 1 & 1 \\
\hline 2006 & 9 & 21 & 5 & 5 & 1 & 1 & & \\
\hline 2007 & 9 & 9 & & & 4 & 4 & & \\
\hline 2008 & 2 & 2 & $2(1)$ & $2(1)$ & 6 & 6 & & \\
\hline 2009 & 3 & 4 & $6(9)$ & $6(9)$ & 4 & 4 & & \\
\hline 2010 & & & & & 7 & 8 & & \\
\hline 2011 & 3 & 3 & & & 11 & 11 & & \\
\hline 2012 & 4 & 4 & & & 5 & 5 & & \\
\hline 2013 & & & & & & & & \\
\hline
\end{tabular}


number of individuals within a subsample to the total catch, whereas species categorized as 'Select' had every individual pulled from the catch and are an exact count.

We do not intend to evaluate the remaining population trends in Shepherd \& Myers (2005). However, we provide one further line of evidence to caution against their use. It is worthy to note that Shepherd \& Myers (2005) also reported that bonnethead shark Sphyrna tiburo populations declined by $96 \%$ in the Gulf of Mexico. Yet, in a 2011 stock assessment for bonnethead sharks in the northwest Atlantic Ocean and Gulf of Mexico (NMFS 2013) that utilized multiple data sources (including the one used by Shepherd \& Myers 2005), the population was not overfished and overfishing was not occurring. Thus, any predictions on the depletions of elasmobranch taxa and predation release by Shepherd \& Myers (2005) should be regarded with caution as there is a misunderstanding of the sampling design associated with the collection of data they analyzed.

While lesser electric rays range widely throughout the Bahamas, Caribbean Sea, and coastal areas of the USA where SCUBA diving is popular, few records of this species were present in the REEF data series. Although Ward-Paige et al. (2011) successfully used data from this survey to analyze spatial and temporal trends in yellow stingray Urobatis jamaicensis, the lack of records for lesser electric rays does not necessarily indicate that the species is in serious decline or rare, but rather may be an artifact of the sampling design and the cryptic nature of the species (e.g. small size and camouflage, resulting in low probability of observation). Recreational divers of varying skill levels conduct the REEF survey and most SCUBA diving activities usually occur in relatively calm areas associated with structures, such as reefs and wrecks, rather than over relatively featureless, sandy bottoms associated with surf zones and barrier islands, where lesser electric rays commonly occur (Rudloe 1989). Accurate identification can also be an issue in these data, as lesser electric rays could be misidentified as yellow stingray (R. D. Grubbs pers. comm.) or Atlantic torpedo ray Torpedo nobiliana (Parsons 2006).

Within the Gulf of Mexico, the distribution of lesser electric ray seems to be heavily concentrated along barrier islands, particularly around south Texas, Mississippi, and Alabama. However, off the coast of Mississippi and Alabama, much of the area is no longer within the sampling universe of the SEAMAP survey. Presently, efforts are being made to include waters as shallow as $3.6 \mathrm{~m}$ in the sampling universe, but there are only a few research vessels that can trawl so shallow with the standardized sampling gear. Regardless, with the proportional allocation of stations by NMFS statistical zone, very few stations may end up in these shallow depths in future survey years. This could lead to a decrease in the capture of lesser electric rays during the survey in the future because SEAMAP is no longer sampling their preferred habitat; therefore, resulting data would not reflect true changes in abundance but rather another change in sampling design. However, it is important to note that when examining trawl data collected at depths outside of the SEAMAP universe off Mississippi and Louisiana, there are still many lesser electric rays captured that were not included in the indices of abundance (Table 1).

Overall, while the lesser electric ray exhibits a patchy distribution over their range, they are fairly abundant in specific habitats while consistently absent from others. Although habitat specificity may subject the species to increased risk of localized harvest, we found no evidence of a decline in the relative abundance of lesser electric rays. The species is still considered Critically Endangered according to IUCN Red List criteria. Thus, an update on the Red List assessment of this species is warranted.

Acknowledgements. Information used in this publication contributed to the NOAA Fisheries Service Status Review of the lesser electric ray. We thank R. Dean Grubbs, Mathew Ajemian, and James Sulikowski for their comments on the status review report, and Nick Dulvy for discussion related to abundance declines.

\section{LITERATURE CITED}

Bigelow HB, Schroeder WC (1953) Sawfishes, guitarfishes, skates and rays. In: Tee-Van J, Breder CM, Parr AE, Schroeder WC, Schultz LP (eds) Fishes of the western North Atlantic, Number 1, Part Two. Sears Foundation for Marine Research, New Haven, CT, p 107-122

Bradu D, Mundlak Y (1970) Estimation in lognormal linear models. J Am Stat Assoc 65:198-211

Coles RJ (1910) Observations on the habits and distribution of certain fishes taken on the coast of North Carolina. Bull Am Mus Nat Hist XXVIII:337-362

de Carvalho MR (1999) A systematic revision of the electric ray genus Narcine Henle, 1834 (Chondrichthyes: Torpediniformes: Narcinidae), and the higher-level phylogenetic relationships of the orders of elasmobranch fishes (Chondrichthyes): (parts 1 and 2). PhD dissertation, City University of New York

de Carvalho, MR, McCord ME, Myers RA (2007) Narcine bancroftii. The IUCN Red List of Threatened Species 2007: e.T63142A12622582. http://dx.doi.org/10.2305/ IUCN.UK.2007.RLTS.T63142A12622582.en. (accessed 04 December 2015) 
Dulvy NK, Fowler SL, Musick JA, Cavanagh RD and others (2014) Extinction risk and conservation of the world's sharks and rays. eLife 3:e00590

Eldridge P (1988) SEAMAP: a state federal-university program for collection, management, and dissemination of fishery independent data and information in the southeastern United States. Mar Fish Rev 50:29-39

Hilborn R, Walters CJ (1992). Quantitative fisheries stock assessment. Chapman \& Hall, New York, NY

Lo NC, Jacobson LD, Squire JL (1992) Indices of relative abundance from fish spotter data based on delta lognormal models. Can J Fish Aquat Sci 49:2515-2516

Marris E (2007) Conservation priorities: what to let go. Nature 450:152-155

Maunder M, Punt A (2004) Standardizing catch and effort data: a review of recent approaches. Fish Res 70:141-159

McEachran JD, de Carvalho MR (2002) Batoid fishes. In: Carpenter KE (ed) The living marine resources of the western central Atlantic: Vol 1. Introduction, molluscs, crustaceans, hagfishes, sharks, batoids fishes and chimaeras. FAO species identification guide for fishery purposes and American Society of Ichthyologists and Herpetologists special publication No. 5. FAO, Rome, p 507-589

National Marine Fisheries Service (NMFS) (2013) SEDAR 34 stock assessment report: HMS Bonnethead Shark. US Department of Commerce, National Marine Fisheries Service, Office of Sustainable Fisheries, Highly Migratory Species Management Division Silver Spring, MD

Nichols S (2004) Derivation of red snapper time series from SEAMAP and groundfish trawl surveys. SEDAR7-DW01, SEDAR, North Charleston, SC

Editorial responsibility: Eric Gilman, Honolulu, Hawaii, USA
Parsons GR (2006) Sharks, skates and rays: a field guide, 1st edn. University Press of Mississippi, Jackson, MS

* Pennington M (1983) Efficient estimators of abundance, for fish and plankton surveys. Biometrics 39:281-286

Pollack AG, Ingram GW (2014) Smoothhound abundance indices from SEAMAP groundfish surveys in the Northern Gulf of Mexico. SEDAR39-DW-07, SEDAR, North Charleston, SC

Pollack AG, Ingram GW (2015) Gray Triggerfish Abundance Indices from SEAMAP Groundfish Surveys in the Northern Gulf of Mexico SEDAR43-WP-11 SEDAR, North Charleston, SC

REEF (2014) Reef Environmental Education Foundation. World Wide Web electronic publication. www.REEF.org. (accessed 3 September 2014)

Rester JK (2015) SEAMAP Environmental and biological atlas of the Gulf of Mexico, 2013. Gulf States Marine Fisheries Commission. www.gsmfc.org/publications/ GSMFC\%20Number\%20239.pdf.

Rudloe A (1989) Habitat preferences, movement, size frequency patterns and reproductive seasonality of the lesser electric ray, Narcine brasiliensis. Northeast Gulf Sci 10:103-112

Shepherd TD, Myers RA (2005) Direct and indirect fishery effects on small coastal elasmobranchs in the northern Gulf of Mexico. Ecol Lett 8:1095-1104

Walters C (2003) Folly and fantasy in the analysis of spatial catch rate data. Can J Fish Aquat Sci 60:1433-1436

Ward-Paige CA, Pattengill-Semmens C, Myers RA, Lotze HK (2011) Spatial and temporal trends in yellow stingray abundance: evidence from diver surveys. Environ Biol Fishes 90:263-276

Submitted: April 15, 2016; Accepted: December 1, 2016 Proofs received from author(s): February 6, 2017 